\title{
Empty Sella Turcica Syndrome: About a Case Revealed by Adrenal Insufficiency
}

\section{Sow Maïmouna1 ${ }^{*}$, Diagne Nafissatou1, Ndao Awa Cheikh1', Thiam Mbaye ${ }^{2}$, Faye Atoumane ${ }^{1}$, Dieng Mouhamed1, Kane Baïdy Sy¹, Djiba Boundia1, Pouye Abdoulaye ${ }^{1}$}

${ }^{1}$ Internal Medicine Department, Aristide Le Dantec Teaching Hospital, Dakar, Senegal

${ }^{2}$ Radiology Department, FANN Teaching Hospital, Dakar, Senegal

Email: *mouna89sow@hotmail.fr

How to cite this paper: Maïmouna, S., Nafissatou, D., Cheikh, N.A., Mbaye, T., Atoumane, F., Mouhamed, D., Sy, K.B., Boundia, D. and Abdoulaye, P. (2021) Empty Sella Turcica Syndrome: About a Case Revealed by Adrenal Insufficiency. Open Journal of Internal Medicine, 11, 68-72. https://doi.org/10.4236/ojim.2021.112005

Received: February 19, 2021

Accepted: April 17, 2021

Published: April 20, 2021

Copyright $\odot 2021$ by author(s) and Scientific Research Publishing Inc. This work is licensed under the Creative Commons Attribution International License (CC BY 4.0).

http://creativecommons.org/licenses/by/4.0/

\section{(c) (i) Open Access}

\begin{abstract}
Background: Empty sella turcica corresponds to an arachnocele which may be complete or partial, primary or secondary. The primary form is rarer. Its cause is unknown, but etiological factors have been identified. The prevalence of this condition is variable, depending on techniques of diagnosis. It may be detected fortuitously on imaging or in the presence of neurological, ocular or endocrine manifestations. Aim: We aim to report a case of empty sella turcica syndrome revealed by adrenal insufficiency in a young African black woman. Case presentation: It was an overweight young woman with signs of intracranial hypertension associated with central adrenal insufficiency. The diagnosis of empty sella was confirmed by magnetic resonance imaging. Secondarily, she developed a hypo metabolism syndrome and biology confirmed central hypothyroidism. After correction of the adrenal cortical deficit, the treatment of the thyroid deficit was administered. Evolution was favourable clinically and biologically. Conclusion: The empty sella turcica is rare and its revelation by a central adrenal insufficiency is even more. The case we report is a perfect illustration.
\end{abstract}

\section{Keywords}

Empty Sella Turcica, Adrenal Insufficiency, Intracranial Hypertension

\section{Introduction}

The empty sella turcica is defined as a hernia of the subarachnoid space in the sella turcica (arachnocele). It can be partial if less than $50 \%$ of the sellar space is filled with cerebrospinal fluid (CSF) or complete. It can also be primary if there is no pathological process in the sellar region preceding the pituitary le- 
sion or secondary related to pathological processes in the region. The primary form, of unknown aetiology, is rarer. Its prevalence varies according to the means of diagnosis used, whether anatomopathological or radiological [1]. In Africa, some cases have been reported [2] [3]. Its discovery may be fortuitous radiological. Endocrine dysfunction and/or neurological manifestations may lead to the diagnosis. Headaches and visual disturbances are the most frequent symptoms [1]. For endocrine dysfunction, the most of time, hormone deficits are multiple. Isolated adrenal insufficiency is a rare presentation of empty sella turcica [4].

We report an observation of a primary empty sella turcica syndrome, revealed by a central adrenal insufficiency.

\section{Observation}

A 38-year-old woman with a history of eclampsia and high blood pressure treated by Amlodipine $10 \mathrm{mg}$ was received at our hospital. She consulted for diffuse and severe headaches, not calmed by the usual analgesics, without triggering factors, associated with rotational type dizziness, easy vomiting in jets, not rhythmed by food. She also reported severe, persistent and progressive physical asthenia, non-selective anorexia and a weight loss of $4 \mathrm{~kg}$ in 2 months.

The physical examination found a conscious patient (Glasgow at 15/15), slightly dehydrated. Her blood pressure was $90 / 60 \mathrm{mmHg}$. She had a temperature of $37^{\circ}$, a pulse rate at 95 cycles per minute and a capillary blood glucose at 0.70 $\mathrm{g} / \mathrm{l}$. She was overweight with a body mass index of $28.7 \mathrm{~kg} / \mathrm{m}^{2}$. The rest of the clinical examination was normal.

Biology showed a low 8-hour cortisol level at $5.38 \mathrm{ng} / \mathrm{ml}(60.2-184 \mathrm{ng} / \mathrm{ml})$ and a normal Adreno Cortico Trophic Hormone (ACTH) level at $28 \mathrm{pg} / \mathrm{ml}$. Thyroid Stimulating Hormone (TSH) was normal at $1.24 \mathrm{mUI} / \mathrm{l}(0.27-4.4 \mathrm{mIU} / \mathrm{l})$ and prolactinemia was at the lower limit of normal. Kidney function and blood ionogram were normal.

Magnetic Resonance Imaging (MRI) showed a partially empty sella without tumour process (Figure 1).

Intravenous hydrocortisone combined with parenteral rehydration was initially instituted. The patient also received analgesic treatment. Secondarily, oral hydrocortisone supplementation was prescribed. The patient was advised to lose weight.

The evolution was favourable with a regression of asthenia, correction of the state of hydration and the cessation of headaches. After 6 months, the patient presented a hypo metabolism syndrome which led to thyroid control showing central hypothyroidism with normal TSH and a lowered free Thyroxine 4 (T4). Thyroid hormone replacement therapy improved the symptoms.

The diagnosis of primary empty sella turcica syndrome was made in view of the clinical manifestations (intracranial hypertension, central adrenal insufficiency and hypothyroidism) and the appearance of partially empty sella on MRI, in the absence of intracranial tumour process. 


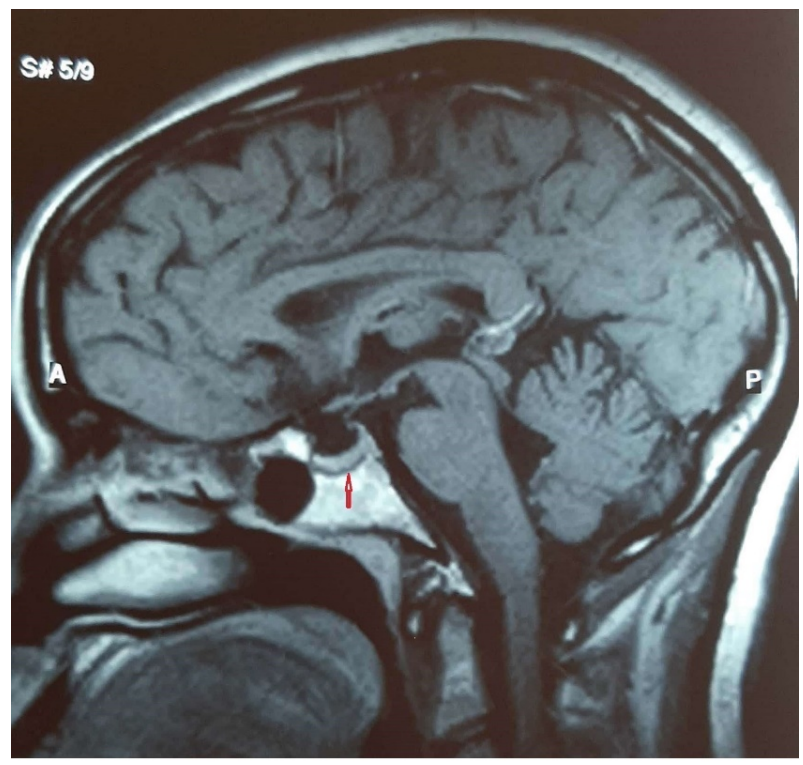

Figure 1. Image of a partially empty sella turcica (red arrow) in cerebral magnetic resonance imaging.

In the follow up, the patient did not present any complications or others symptoms. The control of cortisol and thyroid hormone levels was normal.

\section{Discussion}

Empty sella is characterized by an "empty sella space" on MRI or CT scan with a flattened pituitary gland and an elongated stem. Its prevalence depends on the techniques used for detection. In autopsy studies, empty sellas have been found in up to $5.5 \%$ to $12 \%$ of cases. In imaging, the overall incidence has been estimated at $12 \%$ [1]. It can be partial if less than $50 \%$ of the sellar space is filled with (CSF), or complete if the CSF fills more than $50 \%$ of the space and the thickness of the gland is less than $2 \mathrm{~mm}$ [5].

Our patient presented with a partial form of empty sella turcica.

It can be primary if there is no pathological process in the sellar region preceding the pituitary lesion or secondary [1]. This last is more common and is related to various pathological processes in the sellar region [6].

Primary empty sella appear in subjects without a history of pituitary disease. It can be caused by intracranial hypertension and/or sellar diaphragm failure.

Many factors as obesity, sleep apnoea, high blood pressure, pregnancy and labour can increased intermittently intracranial pressure. Intracranial hypertension may also be idiopathic.

The prevalence of primary empty sella is very high in patients with idiopathic intracranial hypertension. Pituitary gland hyperplasia during pregnancy and lactation and pituitary involution after menopause may also be involved in the pathogenesis of empty sella syndrome, which explains the significantly higher prevalence of this condition in women [1] [5].

Our observation concerns a young woman with factors associated with an 
empty sella, namely high blood pressure and overweight. She presented a symptomatology of intracranial hypertension.

Empty sella can manifest by headaches, endocrine dysfunction and visual disturbances due to pressure on neighbouring structures. Most patients present headache. In $20 \%$ of patients, it may be accompanied by visual disturbances. In case of intracranial hypertension, papilledema may occur [1]. Visual disturbances can include worsening of visual acuity, blurred vision, diplopia, oculomotor nerve abnormalities and optic neuritis [5]. Women of childbearing age may be affected by menstrual irregularities, galactorrhoea and infertility. Men can develop gynecomastia and sexual disorders [1].

The prevalence of hypopituitarism is variable. In a meta-analysis, hypopituitarism was found in 52\%, multiple pituitary hormone deficits were present in $30 \%$ and $21 \%$ of patients had isolated hormone deficit. Growth hormone and gonadotropin deficiencies were the most common isolated deficiencies [2]. Hyperprolactinemia is present in about $10 \%$ of patients. Rarely, empty sella can be associated with pituitary micro adenomas causing acromegaly and Cushing's disease [1].

Central adrenal insufficiency was the circumstance of discovery of the empty sella turcica in our observation. In the literature, an isolated adrenal insufficiency is rarely indicative of this condition [7] [8]. The prevalence of adrenal insufficiency ranged from $4.3 \%$ to $37.5 \%$ in the systematic review on the prevalence of hormonal dysregulation during the empty sella syndrome [4]. Another study reports a $1 \%$ prevalence of adrenal insufficiency [9]. Thyroid damage that appeared secondarily in our observation is more frequently found than adrenal insufficiency [2] [3].

In all cases of empty sella, hormonal evaluation is recommended. A threshold results or suspicion of isolated or partial insufficiency, needs stimulation tests if clinically relevant for hormone supplementation [1].

On imaging, in the typical presentation, the filling of the CSF is in continuity with the overlying subarachnoid spaces and the residual pituitary gland is flattened against the floor of the enlarged bony sella with a generally decreased pituitary volume [10].

The management of primary empty sella syndrome is based on the treatment of the various symptoms. Hormone deficiencies must be supplemented starting with hydrocortisone before thyroid hormone supplementation. Hyperprolactinemia should be treated with dopaminergic agonists [11]. In patients with idiopathic intracranial hypertension, osmotic diuretics or acetazolamide are recommended. Weight loss may be effective in obese and overweight patients, especially if accompanied by sleep apnoea [1].

Supplementation with hydrocortisone and thyroid hormones combined with analgesic treatment has led to a good improvement in the clinical picture.

\section{Conclusion}

This case report illustrated a primary empty sella turcica syndrome revealed by 
adrenal insufficiency. This condition is rare. Clinical manifestations are nonspecific and frustrated. MRI is used to make the diagnosis. The treatment depends on the observed disorders.

\section{Conflicts of Interest}

The authors declare no conflicts of interest regarding the publication of this paper.

\section{References}

[1] Chiloiro, S., Giampietro, A., Bianchi, A., Tartaglione, T., Capobianco, A., Anile, C. and De Marinis, L. (2017) Primary Empty Sella: A Comprehensive Review. European Journal of Endocrinology, 177, 275-285. https://doi.org/10.1530/EJE-17-0505

[2] Ruberti, R.F. and Saio M. (1994) Primary Empty Sella in the Eastern African: Report of Four Cases. African Journal of Neurological Sciences, 13,1.

[3] Izizag, B.B., Ngandu, A. and Mbiso, A.L. (2019) Syndrome de la Selle Turcique Vide: à propos d'un cas. Pan African Medical Journal, 33, 317.

https://doi.org/10.11604/pamj.2019.33.317.17423

[4] Auer, M.K., Stieg, M.R., Crispin, A., Sievers, C., Stalla, G.K. and Kopczak, A. (2018) Primary Empty Sella Syndrome and the Prevalence of Hormonal Dysregulation. Deutsches Artzteblatt International, 115, 99-105. https://doi.org/10.3238/arztebl.2018.0099

[5] Miljic, D., Pekic, S., Popovic, V. (2000) Empty Sella. In: Feingold, K.R., Anawalt, B., Boyce, A., et al., Eds., Endotext [Internet]. South Dartmouth (MA): MDText.com, Inc. https://www.ncbi.nlm.nih.gov/sites/books/NBK532084/

[6] Wael, F. (2011) Review of Empty Sella Syndrome and Its Surgical Management. Alexandria Journal of Medicine, 47, 139-147. https://doi.org/10.1016/j.ajme.2011.06.005

[7] Gulcan, E., Gulcan, A., Taser, F., Korkmaz, U. and Erbilen, E. (2007) May Primary Empty Sella Turcica be a Cause of Isolated ACTH Deficiency? A Case Report and the Review of Related Literature. Neuro Endocrinol Letters, 28, 745-748.

[8] Armengou, A., Fernández-Real, J.M., Ricart, W. and Porcar, C. (1997) Déficit aislado de Hormona Adrenocorticotropa (ACTH) Asociado a Silla Turca Parcialmente vacía [Isolated ACTH Deficiency Associated with Partially Empty Sella Turcica]. Medicina Clínica (Barc), 12, 557-558.

[9] Giustina, A., Aimaretti, G., Bondanelli, M., Buzi, F., Cannavò, S., Cirillo, S., Colao, A., De Marinis, L., Ferone, D., Gasperi, M., Grottoli, S,. Porcelli, T., Ghigo, I. and Uberti, E. (2010) Primary Empty Sella: Why and When to Investigate Hypothalamic-Pituitary Function. Journal of Endocrinological Investigation, 33, 343-346. https://doi.org/10.1007/BF03346597

[10] Hoffmann, J., Schmidt, C., Kunte, H., Klingebiel, R., Harms, L., Huppertz, H.J., Lüdemann, L. and Wiener, E. (2014) Volumetric Assessment of Optic Nerve Sheath and Hypophysis in Idiopathic Intracranial Hypertension. American Journal of Neuroradiology, 35, 513-518. https://doi.org/10.3174/ajnr.A3694

[11] De Marinis, L., Bonadonna, S., Bianchi, A., Maira, G. and Giustina, A. (2005) Primary Empty Sella. Journal of Clinical Endocrinology and Metabolism, 90, 54715477. https://doi.org/10.1210/jc.2005-0288 